\title{
PENYULUHAN TENTANG DAGUSIBU PADA ANGGOTA PKK DI KECAMATAN SINGARAN PATI KELURAHAN LINGKAR TIMUR, KOTA BENGKULU
}

\section{COUNSELING ABOUT DAGUSIBU TO PKK MEMBERS IN DISTRICTS SINGARAN PATI SUBDISTRICT LINGKAR TIMUR, BENGKULU CITY}

\author{
Dwi Dominica $^{1{ }^{*}}$, Reza Pertiwi ${ }^{2)}$, Deni Agus Triawan ${ }^{3)}$ \\ ${ }^{1)}$ Prodi S1-Farmasi, Fakultas Matematika dan Ilmu Pengetahuan Alam, Universitas Bengkulu \\ email: dwidominica@unib.ac.id \\ ${ }^{2)}$ Prodi S1-Farmasi, Fakultas Matematika dan Ilmu Pengetahuan Alam, Universitas Bengkulu \\ email: rpertiwi@unib.ac.id \\ 3) Prodi D3-Lab Sains, Fakultas Matematika dan Ilmu Pengetahuan Alam, \\ Universitas Bengkulu. email: deni.agust@unib.ac.id
}

\begin{abstract}
ABSTRAK
Dampak dari kesalahan pengelolaan obat yang tidak tepat saat membuang obat akan menyebabkan Pencemaran lingkungan sehingga terganggunya keseimbangan ekosistem di sekitar. Salah satu cara pengelolaan obat yang baik dan benar adalah DAGUSIBU. Cara ini menjelaskan tata cara pengelolaan obat dari awal mereka dapatkan hingga saat obat sudah tidak dikonsumsi lagi dan akhirnya dibuang. Tujuan kegiatan pengabdian pada masyarakat ini antara lain : Untuk meningkatkan pemahaman dan meningkatkan kesadaran masyarakat khususnya pada anggota PKK di kecamatan singaran pati kelurahan Lingkar Timur kota Bengkulu agar tidak keliru dalam mendapatkan, menggunakan, menyimpan dan membuang obat. Metode yang digunakan pada kegiatan ini adalah metode pendekatan melalui: Ceramah dan Tanya jawab, yang dilakukan untuk memberikan kesempatan kepada masyarakat apabila ada yang belum dipahamai untuk mengevaluasi keberhasilan penyuluhan. Dari hasil evaluasi kegiatan dan berdasarkan hasil pretest dan post tes yang dilakukan selama kegiatan menunjukkan hasil yang positif dimana terjadi peningkatan pengetahuan masyarakat dalam menggunakan, menyimpan, dan membuang obat dirumah.
\end{abstract}

Kata kunci: Penyuluhan, Sosialisasi, DAGUSIBU, Anggota PKK, Singgaran Pati Kota Bengkulu

\section{ABSTRACT}

The impact of mismanagement of drugs that are not appropriate when disposing of drugs will cause environmental pollution so that the balance of the surrounding ecosystem is disrupted. One way of managing drugs that is good and correct is DAGUSIBU. This method describes the procedures for managing drugs from the beginning they were obtained until the time the drug was no longer consumed and finally discarded. The objectives of this community service activity include: To increase understanding and increase public awareness, especially for PKK members in Singaran pati sub-district, Bengkulu City so that they are not mistaken in obtaining, using, storing and disposing of drugs. The method used in this activity is the approach method through: Lecture and Question and Answer, which is carried out to provide opportunities for the community if there is something that is not understood yet to evaluate the success of counseling. From the results of the evaluation of the activities and based on the results of the pretest and posttests carried out during the activity, it shows positive results where there is an increase in people's knowledge in using, storing and disposing of medicines at home.

Keywords: Counseling, Sosialization, DAGUSIBU, PKK Members, Singgaran Pati at Bengkulu city

\section{PENDAHULUAN}

Obat adalah suatu bahan kimia yang menghilangkan, atau menyembuhkan seseorang dari penyakit yang diderita.

digunakan untuk mencegah, mengurangi, Munculnya berbagai bentuk, jenis, dan 166 
khasiat obat di masyarakat sehingga membuat masyarakat bingung cara penggunaan obat yang baik dan benar serta kebanyakan tidak peduli dengan tata cara pengelolaan obat. Mereka hanya tahu istilah obat hanya untuk dikonsumsi dan supaya sembuh.

Dewasa ini banyak kasus-kasus di masyarakat mengenai penyalahgunaan obat. Baik itu obat yang sudah diresepkan dari dokter karena sakit, maupun obat yang masyarakat dapatkan atas inisiatif mereka sendiri. Kasus-kasus tersebut diantaranya mulai dari keracunan, overdosis, hingga menyebabkan kematian. Mereka menganggap diri mereka tahu cara menggunakan obat dari awal sejak mereka dapatkan hingga akhir.

Menurut Riset Kesehatan Dasar tahun 2013, 35,2\% rumah tangga menyimpan obat untuk penobatan mereka sendiri atau yang dikenal dengan swamedikasi. Kurangnya keingintahuan masyarakat mengenai hal ini sangatlah berbahaya. Mereka tidak boleh menganggap remeh mengenai tata cara pengelolaan obat. Mulai dari awal mereka mendapatkan resep dari doketr, hingga cara membuangnya jika sudah tidak bisa dipakai lagi. Padahal jika sedikit kita salah melakukan pengelolaan obat, maka akan sangat berakibat fatal bagi diri kita sendiri atau si konsumen obat.

Selain itu dampak dari kesalahan pengelolaan obat akan tampak di lingkungan. Pencemaran lingkungan karena pembuangan obat yang sembarangan akan terjadi dan menyebabkan terganggunya keseimbangan ekosistem di sekitar. Hal ini pada akhirnya juga menyebabkan kerugian bagi manusia sendiri. Salah satu cara pengelolaan obat yang baik dan benar adalah DAGUSIBU. Cara ini menjelaskan tata cara pengelolaan obat dari awal mereka dapatkan hingga saat obat sudah tidak dikonsumsi lagi dan akhirnya dibuang. (Lutfiyani, dkk.,2017).

Manfaat yang dihasilkan dari program pengabdian kepada masyarakat tentang DAGUSIBU yaitu : Masyarakat dapat mengetahui apa dan bagaimana itu Cara mendapatkan, menggunakan, menyimpan, dan membuang obat. Masyarakat dapat terhindar dari bahaya mendapatkan, menggunakan, menyimpan, dan membuang obat yang salah itu sendiri. Masyarakat dapat mengedukasi keluarganya ataupun masyarakat lainnya untuk tidak salah dalam mendapatkan, menggunakan, menyimpan, dan membuang obat. Hal ini dapat mendukung terwujudnya program pemerintah dalam meningkatkan kesehatan masyarakat yaitu GKSO (gerakan keluarga sadar obat). Ratnasari, 2019.

\section{METODE PELAKSANAAN KEGIATAN}

Metode yang digunakan pada kegiatan pengabdian ini adalah:

1. Ceramah, yang dilakukan untuk memberikan pengetahuan tentang cara mendapatkan, menggunakan, menyimpan dan membuang obat yang baik dan benar.

2. Diskusi dan Tanya jawab, yang dilakukan untuk memberikan 
kesempatan kepada masyarakat apabila ada yang belum dipahamai untuk mengevaluasi keberhasilan penyuluhan

\section{HASIL DAN PEMBAHASAN}

Pelaksanaa kegiatan penyuluhan dilakukan pada anggota PKK dikecamatan Singgaran Pati Kelurahan Lingkar Timur pada tanggal 24 Oktober 2020 pada pukul 15.30 - 17.30 disalah satu rumah warga. Peserta kegiatan ini memiliki latar belakang pendidikan dan pekerjaan yang beraneka ragam. Latar belakang pendidikan peserta kegiatan ini ada yang lulusan SD, SMP, SMA dan perguruan tinggi. Terkait pekerjaan dari peserta penyuluhan mayoritas pekerjaan peserta disini adalah sebagai ibu rumah tangga dan pedagang. Jumlah peserta penyuluhan berkisar 25 orang.

Penjelasan atau pemaparan materi dilakukan oleh Apoteker sekaligus Dosendosen S1 Farmasi Universitas Bengkulu. Kegiatan ini dimulai dengan pembukaan dan sambutan oleh ketua PKK setempat yang menjelaskan tentang kegiatan penyuluhan ini. Kemudian, dilanjutkan sambutan oleh Ketua pengabdian yang menjelaskan mengenai tujuan, manfaat dan rangkaian kegiatan penyuluhan. Sebelum kegiatan penyuluhan ini akan dimulai peserta diminta mengisi kuisioner atau angket (pre-test) yang telah di siapkan oleh TIM Pengabdian oleh Dosen S1 Farmasi dan rekan-rekan Universitas Bengkulu untuk mengetahui sejauhmana tingkat pengetahuan peserta terkait penggunaan obat dengan benar. Setelah pemaparan materi dan belum kegiatan berakhir juga dilakukan evaluasi kepada pesrta dengan mengisi kuisoner atau angket kembali (post tes).

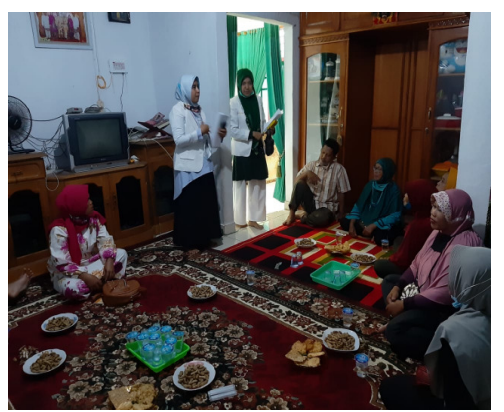

Gambar 1. Saat penyampaian maksud kedatangan pada anggota PKK

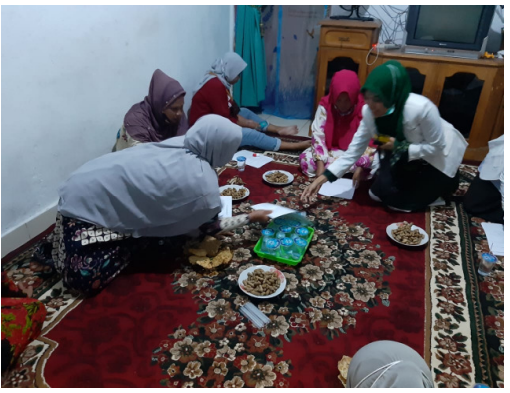

Gambar 2. Pendampingan pengisian kuisoner oleh Apoteker untuk Ibu-ibu yang tidak bisa baca tulis

Pada saat pelaksanaan masyarakat sangat antusias sekali mendengarkan penyampaian materi mulai dari bagaimana menggunaan obat yang baik dan benar, masyarakat juga mulai mengetahui mana obat yang boleh di beli bebas di warung, apotek, atau toko obat, dan mana yang harus dibeli dengan resep dari dokter melalui penandaan masing-masing obat.

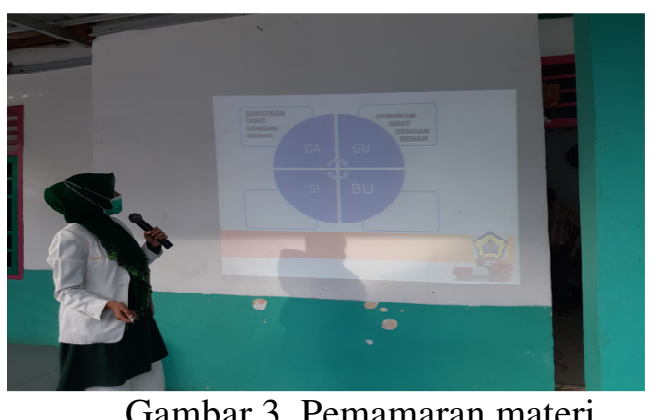

Gambar 3. Pemamaran materi 
Berikut ini adalah uraian dari pemaparan

\section{DAGUSIBU :}

\section{Dapatkan Obat dengan Benar}

Masyarakat mendapatkan obat dengan benar di apotek. Apotek merupakan tempat pelayanan obat resmi, sehingga kita dapat berkonsultasi dengan apoteker di apotek untuk mendapatkan obat yang aman, berkualitas, dan bermanfaat. Tips untuk mendapatkan obat dengan benar yaitu: Perhatikan penggolongan obat, Perhatikan informasi yang terdapat pada brosur dan kemasan, dan Perhatikan kadarluarsa obat.

Mendapatkan obat yang benar dilakukan dengan memperhatikan penggolongan obat, informasi pada kemasan, dan kadaluarsa obat. Masyarakat diharapkan memperoleh obat obatan dari sarana kesehatan yang mempunyai lisensi/legal. Selama ini masyarakat disana ada yang beranggapan jika membeli obat di apotek mereka tidak kunjung sembuh, namun saat mereka meminum obat yang dibeli warung apapun itu mereka sembuh.

Contoh pertanyaan terkait cara mendapatobat dengan benar : .Dibawah ini yang bukan merupakan tempat yang resmi untuk mendapatkan obat ...

a. apotek

b.warung/pegadang kaki lima

c.Toko obat berizin

d. rumah sakit

e. Pusekesmas / klinik

Dari hasil pres test dan post tes yang telah dilakukan maka dapat dilihat maka dari 25 orang peserta yang menjawab benar 19 orang dengan kata lain sudah hamper ratarata mengetahui dimana tempat mendaptkan obat yang resmi walau ada juga sebagian orang yang menjawab salah sekita 6 orang, setelah dilakukan penjelasan makan terjadi perubahan yang positif dengan yang menjawab benar 24 orang dan yang menjawab salah 1 orang. Dapat dilihat dari diagram dibawah ini.

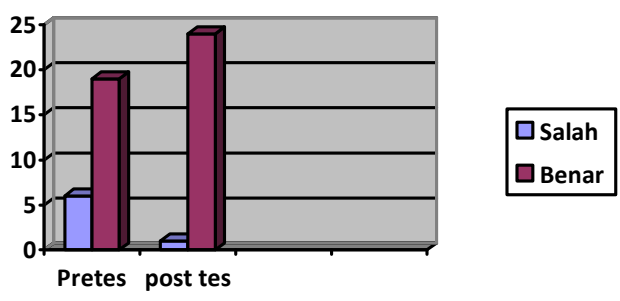

\section{Gunakan Obat dengan Benar}

Masyarakat menggunakan obat dengan benar yaitu dengan cara berkonsultasi dengan apoteker. Penggunaan obat ada beberapa hal yang perlu diperhatikan, seperti:

Tidak terburu-buru mengkonsumsi antibiotic, Obat jenis antibiotik harus diminum sampai habis untuk mecegah timbulnya resistensi, Gunakan obat sesuai petunjuk/aturan yang terdapat dalam kemasan obat.

Menggunakan obat dengan benar sesuai petunjuk pada kemasan obat. Kita dapat menemukan obat dalam jenis dan cara penggunaan yang berbeda-beda. Seperti kapsul, tablet, sirup, suspensi, salep, krim, dan lain-lain. Menurut cara penggunaannya ada obat tetes telinga, hidung, salep mata, suppositoria, dan lain-lain. Dalam penggunaan obat ini, masyarakat harus diedukasi berdasarkan jenis obat apa yang ia terima dan bagaimana cara 
menggunakannya. Oleh karena itu, peran apoteker sangat dibutuhkan di sini. Jangan sampai obat yang seharusnya dimasukkan lewat dubur malah ditelan oleh pasien.

Contoh angket pertanyaan yang diajukan kepada masyarakat terkait menggunakan obat adalah Sering kita mendengar istilah"gunakan obat setelah makan atau sebelum makan".berapa jarak waktu dari sesudah makan/sebelum makan untuk minum obat?

a.sesaat sesudah makan

b. 5 menit -10 menit

c. 10-15 menit

d. 25-40 menit

e. lebih dari 2 jam

Dari hasil pres test dan post tes yang telah dilakukan maka dapat dilihat maka dari 25 orang peserta yang menjawab benar 7 salah 18 orang, setelah dilakukan penjelasan makan terjadi perubahan yang positif dengan yang menjawab benar 22 orang dan yang menjawab salah 3 orang. Dapat dilihat dari diagram dibawah ini.
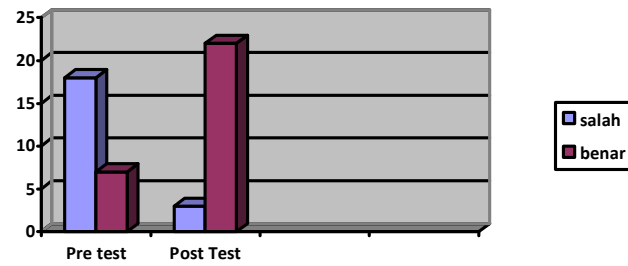

口benar

\section{Simpan Obat dengan Benar}

Masyarakat berkonsultasi dengan apoteker tentang cara penyimpanan obat karena setiap obat memerlukan kondisi penyimpanan yang berbeda. Tips untuk penyimpanan obat dengan benar yaitu: Membaca aturan penyimpanan obat pada kemasan, Menjauhkan dari jangkauan anakanak, Mengunci almari penyimpanan obat dan lain-lain

Menyimpan obat dengan benar sesuai petunjuk pada kemasan. Obat disimpan dalam kondisi tertentu. Pada suhu tertentu dan di tempat yang kering. Sifat obat yang mudah terdegradasi/berubah menjadi senyawa kimia lain dapat menyebabkan obat tidak stabil dalam kondisi tertentu. Biasaya kita temukan kalimat "Jauhkan dari sinar matahari langsung. Simpan pada suhu kamar" dalam sebuah kemasan obat.

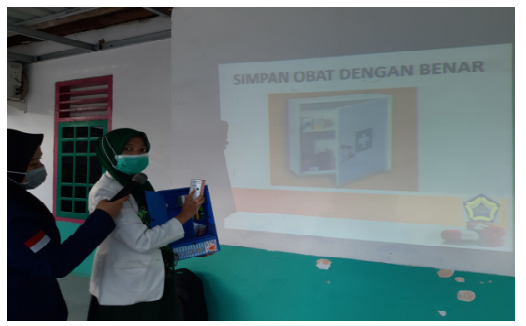

Gambar 4. Peragaan contoh penyimpanan obat dirumah dengan menggunaan kotak P3K

Contoh pernyataan terkait penyimpanan obat yang tepat, berapa lama maksimal waktu penyimpanan sirup kering antibiotik setelah di buka dan digunakan....

a. 2 hari

b. 1 Minggu

c. 2 bulan

d. 6 bulan

e. 1 tahun

Dari hasil pres test dan post tes yang telah dilakukan maka dapat dilihat maka dari 25 orang peserta yang menjawab benar salah 20 orang salah 5 orang, setelah dilakukan penjelasan makan terjadi perubahan yang positif dengan yang menjawab benar 25 orang dan yang menjawab salah 0 orang. Dapat dilihat dari diagram dibawah ini. 


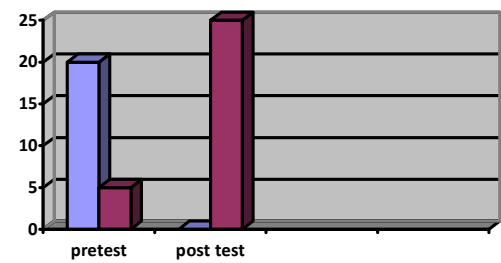

$\square$ Salah
Benar

\section{Buang Obat dengan Benar}

Masyarakat berkonsultasi dengan apoteker agar dapat membuang obat dengan benar. Tips untuk membuang obat dengan benar yaitu: Menghilangkan label pada wadah kemasan, Untuk obat berbentuk tablet dan kapsul dihancurkan dan dicampur dengan tanah, dimasukkan ke plastik, lalu dibuang, Untuk obat antibiotik dibuang dengan kemasan dan hanya labelnya yang dilepaskan dari wadah.

Setelah masa kadaluarsa obat berakhir, maka hendaklah kita membuang obat pada tempatnya. Tempat pembuangan obat sesuai dengan jenis sediaan obat tersebut. Untuk tablet dan sejenisnya (padat), maka obat tersebut dihancurkan dan buang ke tanah yang tidak ditumbuhi tanaman. Untuk cairan, lebih baik dibuang ke tanah juga, karena jika dibuang ke dalam air dapat menyebabkan makhluk hidup di dalam air mati atau terkontaminasi dengan zat kimia obat. Plastik obat, dibuang pada tempat sampah.

Contoh pertanyaan yang diajukan ke masyarakat terkait cara pembuangan obat yang tepat yaitu, salah satu hal yang harus dilakukan terhadap obat yang sudah kadaluarsa atau tidak boleh digunakan lagi...

a) disimpan ditempat tersembunyi agar tidak ada yang menggunakan nya

b) diletakkan dilemari es agar obat tersebut bisa digunakan kembali

c) dicampur dengan obat baru agar bisa digunakan lagi

d) dibuang dengan cara dihancurkan dan dicampur dengan tanah /air/bahan kotor lainnya.

e) semua jawaban salah

Dari hasil pres test dan post tes yang telah dilakukan maka dapat dilihat maka dari 25 orang peserta yang menjawab benar salah 12 orang salah 13 orang, setelah dilakukan penjelasan makan terjadi perubahan yang positif dengan yang menjawab benar 25 orang dan yang menjawab salah 0 orang. Dapat dilihat dari diagram dibawah ini.
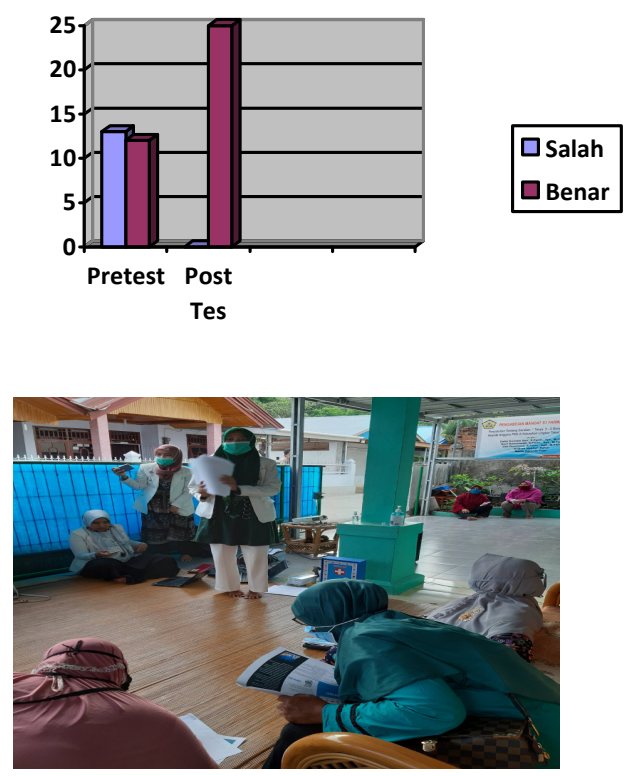

Gambar 5. Peserta melakukan pengisian kuisoner saat post test

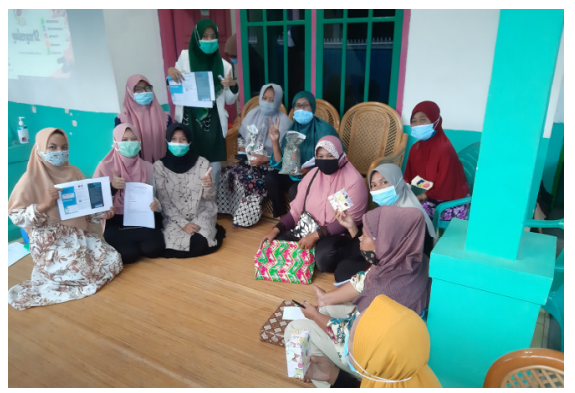

Gambar 6. Foto bersama ibu-ibu yang mendapatkan reward dari post tertinggi 
Salah satu pengembangan dari edukasi dan penyuluhan tentang DAGUSIBU ini adalah dengan pembentukan kader yang nantinya dapat membantu masyarakat sekitar dalam penerapan DAGUSIBU, misalnya melalui metode CBIA (Cara Belajar Ibu Aktif) (Djuria, 2018).

\section{KESIMPULAN}

Pelaksanaan penyuluhan tentang "DAGUSIBU" di Kecamatan Singgaran Pati Kelurahan Lingkar Kota Bengkulu telah terlaksana dengan baik dan mendapatkan respon yang sangat baik dari peserta, yaitu ibu-ibu PKK setempat. Pelaksanaan penyuluhan dan pelatihan mengenai obat terutama Dagusibu dapat dikatakan efektif dengan persentase menjawab benar masingmasing mendapatkan obat yang baik $96 \% \%$, mengunakan obat $88 \%$, SImpan $100 \%$, dan BUang 100\%.

\section{UCAPAN TERIMAKASIH}

Saran untuk kegiatan pengabdian masyarakat berikutnya diharapkan dapat memperluas khalayak sasaran supaya semakin luas masyarakat yang memahami DAGUSIBU obat dengan baik dan benar. Mengingat saat penyuluhan ini berlangsung masih dalam kedaan pandemi covid-19 sehingga tidak boleh warga berkumpul terlalu banyak.

Penulis mengucapkan terima kasih kepada pihak yang telah banyak membantu dalam pengabdian ini. Ucapan terima kasih terutama penulis ucapkan kepada Lembaga Penelitian dan Pengabdian Masyarakat dan Fakultas Matematika dan Ilmu Pengetahuan Alam Universitas Bengkulu, serta ibi-ibu anggota PKK di Kecamatan Singgaran Pati Kelurahan Lingkar Timur atas kesempatan yang diberikan dalam melaksanakan pengabdian mandat S1 Farmasi ini.

\section{REFERENSI}

[1] Djuria, R. F. (2018). Peningkatan pengetahuan tentang DAGUSIBU terhadap kader Gerakan keluarga sadar obat (GKSO) desa Tanjung Gunung Bangka Tengah. Jurnal Kesehatan Poltekkes Pangkalpinang, 6(1), 33-38

[2] Kemenkes RI. (2011). Modul Penggunaan Obat Rasional. Jakarta: Kementerian Kesehatan Republik Indonesia.

[3] Lutfiyati, Heni.,dkk., 2017, Pemberdayaan Kader PKK dalam Penerapan DAGUSIBU(Dapatkan, Gunakan, Simpan, dan Buang) Obat dengan Baik dan Benar, The 6th University Research Colloquium

[4] PP IAI. 2014. Pedoman Pelaksanaan Gerakan Keluarga Sadar Obat. Pengurus Pusat Ikatan Apoteker Indonesia. Jakarta.

[5] Ratnasari, D, dkk. 2019. Penyuluhan Dapatkan - Gunakan - Simpan - Buang (DAGUSIBU) Obat. Program studi D3 Farmasi, Universitas Muhammadiyah Gresik. JCEE. Vol: 01. No: 02. Hal: 5561

[6] Wulandari, dkk. 2019. Pengaruh Edukasi Dan Simulasi Dagusibu Obat Terhadap Peningkatan Keluarga Sadar Obat Di Desa Kedungbanteng Banyumas. Jati Emas (Jurnal Aplikasi Teknik dan Pengabdian Masyarakat) Vol. 3 No. 1 Maret 2019 - e. ISSN: 2550-0821 